\title{
CORRECTION
}

\section{Correction: Normal weight obesity and unaddressed cardiometabolic health risk - a narrative review}

Nadeeja Niranjalie Wijayatunga (iD) and Emily Jane Dhurandhar

(c) The Author(s), under exclusive licence to Springer Nature Limited 2021

International Journal of Obesity (2021) 45:2511; https://doi.org/10.1038/s41366-021-00925-z

Correction to: International Journal of Obesity; https://doi.org/ 10.1038/s41366-021-00858-7

The original version of this article unfortunately contained a mistake in the legend of Figure 1. The correct figure legend should read "Figure 1 was created using images obtained from Smart Servier Medical Art (smart.servier.com) CC BY 3.0". The authors apologize for the mistake. The original article has been corrected. 